\title{
Mortality attributable to cigarette smoking in Taiwan: a 12-year follow-up study
}

\author{
Kuo-Meng Liaw, Chien-Jen Chen
}

\begin{abstract}
Background-Assessment of the impact of cigarette smoking on mortality helps to indicate the importance of tobacco control in a given country.

Objectives-To examine the relative risk of dying from various diseases for cigarette smoking and to estimate annual mortality attributable to cigarette smoking in Taiwan.

Design-Prospective cohort study.

Subjects and setting-A cohort of 14397 male and female residents aged 40 years or older recruited from 12 townships and precincts in Taiwan from 1982 to 1986. Information on cigarette smoking was collected from each subject at local health centres through a standardised personal interview based on a structured questionnaire. They were followed up regularly to determine their vital status until 1994.

Main outcome measures-Cox's proportional hazards regression models were used to derive relative risks of causespecific mortality for current cigarette smokers compared with never-smokers, and to examine dose-response relationships between mortality from various causes and several measures of cigarette smoking (daily consumption, duration, age of initiation, and cumulative smoking in pack-years).
\end{abstract}

Results-A total of 2552 persons died during the study period. Among men, cigarette smoking was significantly associated with an increased risk of dying from all causes combined (relative risk $(R R)=$ $1.3)$; cancer of all sites combined $(R R=$ $1.5)$; cancers of the stomach $(R R=1.9)$, liver $(R R=2.2)$, and lung $(R R=3.7)$; ischaemic heart disease $(R R=1.8)$; other heart diseases $(R R=1.4)$; and chronic obstructive pulmonary disease $(\mathbf{R R}=$ 1.9). Among women, cigarette smoking was significantly associated with an increased risk of dying from all causes combined $(R R=1.8)$, cancer of the lung $(R R=3.6)$, and peptic ulcer $(R R=17.8)$. The estimated number of deaths attributable to cigarette smoking in Taiwan in 1994 was 8161 (13.9\% of total deaths) for men and 1216 (3.3\% of total deaths) for women. In the same year cigarette smoking caused $21.3 \%$ and $2.9 \%$ of cancer deaths in men and women, respectively, in Taiwan.

Conclusions-Cigarette smoking has a striking impact on overall mortality and deaths from various causes in the Taiwanese population. Tobacco control should be established as the top priority in public health programmes in Taiwan.

\section{(Tobacco Control 1998;7:141-148)}

Keywords: mortality, smoking-attributable diseases, Taiwan

Introduction

Evidence of the adverse health effects of tobacco smoking and the benefits of smoking cessation has accumulated during the second half of the 20th century. Numerous prospective studies on cigarette smoking and health hazards have been published..$^{1-13}$ These reports identified cigarette smoking as an important cause of several types of cancer, cardiovascular diseases, chronic bronchitis, emphysema, and many other diseases. However, most epidemiological findings were derived from major prospective studies carried out among North American, European, and other white populations.

Only a few prospective studies have been reported from developing countries. A prospective study was carried out to evaluate the health risks of cigarette smoking in middleaged men in Shanghai. ${ }^{14}$ This study showed that $36 \%$ of all cases of cancer and $21 \%$ of all deaths could be attributed to cigarette smoking. The results are important because this study was the first to assess the hazards of cigarette smoking in Chinese men. However, there remain no data on tobacco-related health hazards in Chinese women, who smoke far less than Western women.

The prevalence of cigarette smoking in Taiwan increased strikingly after the second world war and reached its plateau in the 1960s. ${ }^{15}$ The incidence of and mortality from lung cancer has increased eightfold between the 1960s and 1990s. If the latent period for cigarette smoking to induce lung cancer is about 20-30 years, as documented previously, it is reasonable to attribute most of the increase in lung cancer mortality and morbidity to cigarette smoking.

Cigarette smoking has become the most important health problem in Taiwan. We studied a cohort of Taiwanese residents, including men and women, to assess mortality related to cigarette smoking over a 12 -year span. This is the first prospective study on cigarette smoking and deaths from various causes in Taiwan. 
Table 1 Sociodemographic characteristics and smoking status in the study cohort

\begin{tabular}{|c|c|c|c|c|}
\hline \multirow[b]{2}{*}{ Characteristics } & \multicolumn{2}{|l|}{ Males } & \multicolumn{2}{|c|}{ Females } \\
\hline & $n$ & $(\%)$ & $n$ & $(\%)$ \\
\hline \multicolumn{5}{|l|}{ Age (years) } \\
\hline $41-50$ & 3618 & $(32.6)$ & 1402 & $(42.5)$ \\
\hline $51-60$ & 3946 & $(35.5)$ & 1033 & $(31.3)$ \\
\hline $61-70$ & 2536 & $(22.9)$ & 638 & (19.3) \\
\hline$\geqslant 71$ & 1002 & $(9.0)$ & 228 & $(6.9)$ \\
\hline \multicolumn{5}{|l|}{ Educational level } \\
\hline $\begin{array}{l}\text { No formal } \\
\text { education }\end{array}$ & 1808 & $(16.3)$ & 1857 & $(56.3)$ \\
\hline Elementary school & 6556 & $(59.1)$ & 1196 & $(36.2)$ \\
\hline High school & 2016 & $(18.2)$ & 184 & $(5.6)$ \\
\hline College or above & 498 & $(4.5)$ & 24 & $(0.7)$ \\
\hline Unknown & 218 & (2.0) & 40 & $(1.2)$ \\
\hline \multicolumn{5}{|l|}{ Residence } \\
\hline Metropolitan & 1029 & (9.3) & 965 & $(29.2)$ \\
\hline Urban & 3281 & $(29.6)$ & 597 & $(18.1)$ \\
\hline Rural & 6198 & $(55.9)$ & 1160 & $(35.1)$ \\
\hline Unknown & 588 & $(5.3)$ & 579 & $(17.5)$ \\
\hline \multicolumn{5}{|l|}{ Smoking status } \\
\hline Never-smoker & 4613 & $(41.6)$ & 3160 & $(95.7)$ \\
\hline Former smoker & 1258 & (11.3) & 11 & $(0.3)$ \\
\hline Current smoker & 5225 & $(47.1)$ & 130 & (3.9) \\
\hline Total & 11096 & $(100.0)$ & 3301 & $(100.0)$ \\
\hline
\end{tabular}

\section{Methods}

COHORT RECRUITMENT AND INCLUSION CRITERIA Between October 1982 and March 1986, 12 townships and precincts (Nankang, Nantzu, Tayuan, Tashu, Tounan, Chunan, Kuanhsi, Hsinpu, Hengshan, Yuanshan, Chutien, and Checheng) were selected as the study areas for the prospective study of multiple risk factors for major diseases in Taiwan. These areas were selected to represent metropolitan precincts and urban and rural townships in the north, middle, and south of Taiwan. Residents in the study areas were invited to participate provided they were at least 18 years old and had no previous history of cancer or other major diseases such as cardiovascular disease, diabetes mellitus, or hypertension. Informed consent was given verbally in the presence of a witness. This study received approval and grant funding from the Department of Health and conformed to the provision of the World Medical Assembly in Tokyo in 1975. A total of 17538 residents (25\% of eligible subjects) participated in the study.

DATA COLLECTION

All participants were interviewed at recruitment by well-trained public health nurses in local health centres in the study townships and precincts. The standardised interview was based on a pre-tested, structured questionnaire which inquired about sociodemographic characteristics, history of cigarette smoking and alcohol drinking, vegetarian habit, frequency of consuming various food items, personal and family history of various cancers and major diseases. With respect to history of cigarette smoking and alcohol drinking, the age starting the behaviour, usual consumption quantity, and lifetime consumption duration were assessed. Subjects were followed up for cigarette smoking and alcohol drinking by either home visit or telephone interview from 1989 to 1993 , and changes in these behaviours were recorded.

Ever-smokers were defined as those who had smoked for at least six months at recruitment.
They were further grouped as current smokers or ex-smokers. Ex-smokers were defined as those who had abstained from cigarette smoking during the six months immediately preceding recruitment, or who had quit smoking and remained abstinent for at least six months during the follow-up period (and were still abstinent at the time of the follow-up visit or interview). Current smokers were those who had never quit cigarette smoking at the time of recruitment or during the follow-up period. Almost all tobacco users in Taiwan smoke cigarettes; they rarely use chewing tobacco or snuff.

MORBIDITY AND MORTALITY FOLLOW UP AND

DATA LINKAGE

Study subjects were followed up for their health status during 1989-1993. The occurrence of major diseases was investigated at the hospitals or clinics where the diagnosis was made. To validate vital status and cause of death among study subjects, computerised annual data files of the death certification system in Taiwan during the entire 12-year study period were used to link with identification profiles of subjects. In Taiwan, every newborn is given a national identification number. The

Table 2 Sex-specific prevalence of cigarette smoking (\%) by age, residence, and educational level, in the study cohort and the general population in Taizuan, 1994*

\begin{tabular}{|c|c|c|c|c|}
\hline & \multicolumn{2}{|l|}{ Men } & \multicolumn{2}{|l|}{ Women } \\
\hline & $\begin{array}{l}\text { General } \\
\text { population }\end{array}$ & $\begin{array}{l}\text { Study } \\
\text { cohort }\end{array}$ & $\begin{array}{l}\text { General } \\
\text { population }\end{array}$ & $\begin{array}{l}\text { Study } \\
\text { cohort }\end{array}$ \\
\hline \multirow{2}{*}{\multicolumn{5}{|c|}{$\begin{array}{l}\text { lotal } \\
\text { Age (years) }\end{array}$}} \\
\hline & & & & \\
\hline $41-45$ & 54.3 & 56.4 & 3.5 & 1.7 \\
\hline $46-50$ & 56.4 & & 3.2 & \\
\hline $51-55$ & 59.5 & 60.7 & 3.4 & 3.9 \\
\hline $56-60$ & 59.4 & & 4.2 & \\
\hline $61-65$ & 54.4 & 57.8 & 5.4 & 5.8 \\
\hline $66-70$ & 49.5 & & 5.4 & \\
\hline & 49.3 & 54.0 & 4.5 & 7.5 \\
\hline \multicolumn{5}{|l|}{ Residence } \\
\hline Rural & 51.1 & 59.3 & 4.1 & 2.4 \\
\hline Urban & 56.7 & 53.3 & 2.5 & 1.4 \\
\hline Metropolitan & 59.7 & 62.1 & 2.4 & 6.8 \\
\hline \multicolumn{5}{|l|}{ Educational level } \\
\hline $\begin{array}{l}\text { Not formally } \\
\text { educated }\end{array}$ & & & & \\
\hline $\begin{array}{l}\text { educated } \\
\text { Elementary school }\end{array}$ & $\begin{array}{l}5.2 \\
60.8\end{array}$ & 59.3 & $\begin{array}{l}5.2 \\
3.5\end{array}$ & 2.5 \\
\hline High school & 60.8 & 51.8 & 3.2 & 8.2 \\
\hline College or above & 34.4 & 41.0 & 1.4 & $\begin{array}{l}.02 \\
8.3\end{array}$ \\
\hline
\end{tabular}

* See reference 15 .

Table 3 Characteristics of cigarette smoking among current smokers at recruitment

\begin{tabular}{|c|c|c|c|c|}
\hline \multirow{2}{*}{$\begin{array}{l}\text { Cigarette smoking } \\
\text { characteristics }\end{array}$} & \multicolumn{2}{|l|}{ Men } & \multicolumn{2}{|c|}{ Women } \\
\hline & $n$ & $(\%)$ & $n$ & $(\%)$ \\
\hline \multicolumn{5}{|c|}{ Daily cigarette consumption (cigarettes/day) } \\
\hline $1-10$ & 2638 & $(34.1)$ & 102 & $(78.5)$ \\
\hline $11-20$ & 4463 & $(57.7)$ & 24 & $(18.5)$ \\
\hline$\geqslant 21$ & 640 & $(8.3)$ & 4 & $(3.1)$ \\
\hline \multicolumn{5}{|c|}{ Duration of cigarette smoking (years) } \\
\hline $1-20$ & 1397 & $(18.0)$ & 45 & $(34.6)$ \\
\hline $21-30$ & 2234 & $(28.9)$ & 31 & $(23.8)$ \\
\hline$\geqslant 31$ & 4110 & $(53.1)$ & 54 & $(41.5)$ \\
\hline \multicolumn{5}{|c|}{ Cumulative cigarette smoking $\star$} \\
\hline $1-20$ & 3135 & $(40.5)$ & 103 & $(79.2)$ \\
\hline $21-40$ & 3377 & $(43.6)$ & 22 & $(16.9)$ \\
\hline$\geqslant 41$ & 1229 & $(53.1)$ & 5 & $(3.8)$ \\
\hline \multicolumn{5}{|c|}{ Age starting smoking (years) } \\
\hline$<20$ & 4063 & $(52.5)$ & 39 & $(30.0)$ \\
\hline $20-24$ & 1660 & $(21.4)$ & 12 & $(9.2)$ \\
\hline$\geqslant 25$ & 2018 & $(26.1)$ & 79 & $(60.8)$ \\
\hline
\end{tabular}
smoking (years) $\times$ average packs of cigarettes smoked per day. 
Table 4 Relative risks (RR) and 95\% confidence intervals (CI) of dying from various causes of death for current cigarette smokers compared with never-smokers as the referent group

\begin{tabular}{|c|c|c|c|c|c|c|}
\hline \multirow[b]{2}{*}{ Cause of death } & \multicolumn{3}{|l|}{ Males } & \multicolumn{3}{|l|}{ Females } \\
\hline & $\begin{array}{l}\text { Number of } \\
\text { deaths }\end{array}$ & $R R$ & $(95 \% C I)$ & $\begin{array}{l}\text { Number of } \\
\text { deaths }\end{array}$ & $R R$ & $(95 \% C I)$ \\
\hline All causes combined & 2055 & 1.3 & $(1.2-1.4)$ & 497 & 1.8 & $(1.3-2.5)$ \\
\hline \multicolumn{7}{|l|}{ Cancer } \\
\hline All sites combined & 454 & 1.5 & $(1.2-1.9)$ & 93 & 1.7 & $(0.8-3.7)$ \\
\hline Lip, oral cavity, and pharynx & 13 & 4.2 & $(0.5-32.9)$ & 0 & * & \\
\hline Nasopharynx & 16 & 3.9 & $(0.9-17.0)$ & 2 & $\star$ & \\
\hline Oesophagus & 26 & 1.0 & $(0.4-2.6)$ & 1 & 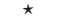 & \\
\hline Stomach & 57 & 1.9 & $(1.0-3.5)$ & 12 & $\star$ & \\
\hline Colon and rectum & 42 & 0.8 & $(0.4-1.5)$ & 2 & $\star$ & \\
\hline Liver & 110 & 2.2 & $(1.4-3.6)$ & 18 & * & \\
\hline Pancreas & 15 & 0.3 & $(0.1-0.9)$ & 4 & $\star$ & \\
\hline Trachea, bronchus, and lung & 105 & 3.7 & $(2.1-6.6)$ & 22 & 3.6 & $(1.0-12.2)$ \\
\hline Cervix uteri & $\star$ & $\star$ & & 6 & 5.3 & $(0.6-46.8)$ \\
\hline Urinary bladder and other urinary & 12 & 0.5 & $(0.2-1.7)$ & 1 & $\star$ & \\
\hline \multicolumn{7}{|l|}{ Other diseases } \\
\hline Ischaemic heart disease & 143 & 1.8 & $(1.2-2.6)$ & 23 & 1.9 & $(0.4-8.4)$ \\
\hline Other heart diseases & 143 & 1.4 & $(1.0-2.0)$ & 49 & 1.5 & $(0.5-4.3)$ \\
\hline Cerebrovascular disease & 326 & 1.0 & $(0.8-1.2)$ & 93 & 1.0 & $(0.4-2.6)$ \\
\hline Arterial disease & 12 & 3.0 & $(0.7-13.7)$ & 2 & 夫 & \\
\hline Chronic obstructive pulmonary diseases & 59 & 1.9 & $(1.0-3.5)$ & 10 & $\star$ & \\
\hline Peptic ulcer & 12 & 4.5 & $(0.6-36.4)$ & 5 & 17.8 & $(2.9-108.0)$ \\
\hline
\end{tabular}

^Relative risk was not estimated due to small number of deaths.

All analyses were adjusted for age and other potential risk factors. See text for details.

Table 5 Relative risks (RR) and 95\% confidence intervals (CI) of dying from major diseases according to level of cigarette consumption among cigarette smokers at recruitment compared with never-smokers as the referent group

\begin{tabular}{|c|c|c|c|c|c|c|c|}
\hline \multirow[b]{3}{*}{ Cause of death } & \multicolumn{6}{|c|}{ Daily cigarette consumption } & \multirow[b]{3}{*}{$p$} \\
\hline & \multicolumn{2}{|l|}{$\leqslant 10$} & \multicolumn{2}{|c|}{$11-20$} & \multicolumn{2}{|l|}{$>20$} & \\
\hline & $R R$ & $(95 \% C I)$ & $R R$ & $(95 \% C I)$ & $R R$ & $(95 \% C I)$ & \\
\hline All causes combined & 1.39 & $(1.24-1.55)$ & 1.20 & $(1.07-1.34)$ & 1.65 & $(1.35-2.02)$ & $<0.01$ \\
\hline \multicolumn{8}{|l|}{ Cancer } \\
\hline All sites combined & 1.4 & $(1.1-1.8)$ & 1.5 & $(1.2-1.9)$ & 2.4 & $(1.7-3.5)$ & $<0.01$ \\
\hline Lip, oral cavity, and pharynx & 2.3 & $(0.2-25.5)$ & 4.7 & $(0.6-38.8)$ & 7.5 & $(0.7-86.7)$ & 0.05 \\
\hline Nasopharynx & 3.6 & $(0.8-16.3)$ & 3.3 & $(0.8-14.0)$ & 3.1 & $(0.3-31.5)$ & 0.13 \\
\hline Oesophagus & 0.8 & $(0.2-2.8)$ & 1.5 & $(0.6-4.2)$ & 2.0 & $(0.4-10.2)$ & 0.25 \\
\hline Stomach & 1.7 & $(0.9-3.4)$ & 1.6 & $(0.8-3.1)$ & 3.0 & $(1.1-8.3)$ & 0.06 \\
\hline Liver & 2.1 & $(1.2-3.5)$ & 1.9 & $(1.2-3.2)$ & 1.8 & $(0.7-4.5)$ & 0.02 \\
\hline Trachea, bronchus, and lung & 3.1 & $(1.7-5.6)$ & 3.6 & $(2.0-6.4)$ & 8.3 & $(4.0-17.3)$ & $<0.01$ \\
\hline \multicolumn{8}{|l|}{ Other diseases } \\
\hline Ischaemic heart disease & 1.9 & $(1.2-2.9)$ & 1.6 & $(1.0-2.4)$ & 2.8 & $(1.4-5.5)$ & 0.01 \\
\hline Chronic obstructive pulmonary disease & 1.7 & $(0.9-3.3)$ & 2.0 & $(1.1-3.9)$ & 0.8 & $(0.1-6.0)$ & 0.09 \\
\hline Peptic ulcer & 9.9 & $(2.1-47.2)$ & 9.1 & $(1.6-52.5)$ & $\star$ & & 0.08 \\
\hline
\end{tabular}

${ }^{\star}$ Relative risk was not estimated due to the small number of deaths.

All analyses were adjusted for age and other potential risk factors. See text for details.

identification profile of this study contained national identification numbers of subjects. As it is mandatory to register any vital event (including death) in Taiwan, death certification is quite complete. All of the causes of death were classified according to the International Classification of Diseases (ICD-9) coding scheme. As the last date of the most up-to-date national certification profile was 31 December 1994, that date was set as the censoring date of the follow up.

STATISTICAL ANALYSIS

The data analysis was based only on mortality for study subjects aged 40 and older, because cigarette smoking was considered to result in mortality of smokers after an induction period of 20 or more years. Among 17538 men and women recruited into the study cohort, 14397 were aged 40 and above. Only 61 of them were not able to be linked with death certification profile, because they did not give their identification numbers at recruitment. The average follow-up period was 9.8 years per subject, and the total person-years of follow up was 140493 years.
Cox's proportional hazards model was used to examine the relationship between smoking status and subsequent risks of dying from various causes among cohort members. Relative risks (RR) of dying from specific causes were thus derived by comparing current smokers with never-smokers as the referent group. Dose-response relationships were also assessed between the risk of dying from various causes and the duration of smoking, quantity smoked, age of smoking initiation, and cumulative cigarette smoking. Cumulative cigarette smoking (in pack-years) was defined as the duration of smoking (in years) multiplied by the average packs of cigarettes smoked per day.

All analyses were adjusted for age, sex, and other potential risk factors for various cancers. We adjusted for alcohol drinking in analyses of mortality from all causes combined, all cancer sites combined, oral cancer, oesophageal cancer, stomach cancer, peptic ulcer, hepatocellular carcinoma, and liver cirrhosis. Carrier status for hepatitis B virus surface antigen was adjusted for, in analyses of mortality from hepatocellular carcinoma and liver cirrhosis. We adjusted for blood pressure in 
Table 6 Relative risks (RR) and 95\% confidence intervals (CI) of dying from major diseases according to duration of smoking among cigarette smokers at recruitment compared with never-smokers as the referent group

\begin{tabular}{|c|c|c|c|c|c|c|c|}
\hline \multirow[b]{3}{*}{ Cause of death } & \multicolumn{6}{|c|}{ Duration of smoking (years) } & \multirow[b]{3}{*}{$p$} \\
\hline & \multicolumn{2}{|l|}{$\leqslant 20$} & \multicolumn{2}{|l|}{$21-30$} & \multicolumn{2}{|l|}{$>30$} & \\
\hline & $R R$ & $(95 \% C I)$ & $R R$ & $(95 \% C I)$ & $R R$ & $(95 \% C I)$ & \\
\hline All causes combined & 1.26 & $(1.07-1.49)$ & 1.25 & $(1.06-1.48)$ & 1.32 & $(1.20-1.47)$ & $<0.01$ \\
\hline \multicolumn{8}{|l|}{ Cancer } \\
\hline All sites combined & 0.9 & $(0.6-1.4)$ & 1.2 & $(0.8-1.6)$ & 1.8 & $(1.4-2.2)$ & $<0.01$ \\
\hline Lip, oral cavity, and pharynx & $\star$ & & 6.0 & $(0.6-55.2)$ & 4.5 & $(0.5-38.4)$ & 0.08 \\
\hline Nasopharynx & 4.4 & $(0.8-23.5)$ & 2.6 & $(0.5-14.4)$ & 3.5 & $(0.8-15.1)$ & 0.22 \\
\hline Oesophagus & $\star$ & & 2.4 & $(0.7-8.9)$ & 1.3 & $(0.5-3.4)$ & 0.43 \\
\hline Stomach & 1.7 & $(0.7-4.4)$ & 0.7 & $(0.2-2.4)$ & 2.0 & $(1.1-3.7)$ & 0.04 \\
\hline Liver & 1.6 & $(0.8-3.2)$ & 1.0 & $(0.5-2.1)$ & 2.5 & $(1.6-4.1)$ & $<0.01$ \\
\hline Trachea, bronchus, and lung & 0.9 & $(0.3-3.1)$ & 2.6 & $(1.2-5.9)$ & 4.7 & $(2.7-8.2)$ & $<0.01$ \\
\hline \multicolumn{8}{|l|}{ Other diseases } \\
\hline Ischaemic heart disease & 2.0 & $(1.1-3.6)$ & 1.0 & $(0.5-2.1)$ & 1.9 & $(1.3-2.8)$ & 0.01 \\
\hline $\begin{array}{l}\text { Chronic obstructive pulmonary } \\
\text { disease }\end{array}$ & 1.8 & $(0.7-4.8)$ & 2.3 & $(0.7-7.1)$ & 1.8 & $(1.0-3.2)$ & 0.07 \\
\hline Peptic ulcer & 5.4 & $(0.5-56.1)$ & 16.9 & $(2.8-103.5)$ & 8.7 & $(1.7-45.6)$ & 0.07 \\
\hline
\end{tabular}

^Relative risk was not estimated due to the small number of deaths.

All analyses were adjusted for age and other potential risk factors. See text for details.

Table 7 Relative risks (RR) and 95\% confidence intervals (CI) of dying from major diseases according to age of smoking initiation among cigarette smokers at recruitment compared with never-smokers as the referent group

\begin{tabular}{|c|c|c|c|c|c|c|c|}
\hline \multirow[b]{3}{*}{ Cause of death } & \multicolumn{6}{|c|}{ Age of smoking initiation (years) } & \multirow[b]{3}{*}{$p$} \\
\hline & \multicolumn{2}{|l|}{$\leqslant 20$} & \multicolumn{2}{|c|}{$21-24$} & \multicolumn{2}{|l|}{$>24$} & \\
\hline & $R R$ & $(95 \% C I)$ & $R R$ & $(95 \% C I)$ & $R R$ & $(95 \% C I)$ & \\
\hline All causes combined & 1.38 & $(1.24-1.54)$ & 1.30 & $(1.12-1.50)$ & 1.18 & $(1.04-1.35)$ & $<0.01$ \\
\hline \multicolumn{8}{|l|}{ Cancer } \\
\hline All sites combined & 1.7 & $(1.4-2.2)$ & 1.7 & $(1.3-2.3)$ & 1.0 & $(0.7-1.4)$ & $<0.01$ \\
\hline Lip, oral cavity, and pharynx & 5.7 & $(0.7-46.1)$ & $\star$ & & 4.5 & $(0.5-43.5)$ & 0.11 \\
\hline Nasopharynx & 3.3 & $(0.8-14.1)$ & 4.8 & $(1.0-23.5)$ & 2.8 & $(0.5-14.8)$ & 0.07 \\
\hline Oesophagus & 1.3 & $(0.5-3.6)$ & 1.5 & $(0.4-5.3)$ & 1.1 & $(0.3-4.0)$ & 0.62 \\
\hline Stomach & 2.2 & $(1.2-4.2)$ & 0.6 & $(0.2-2.2)$ & 1.5 & $(0.7-3.3)$ & 0.02 \\
\hline Liver & 2.2 & $(1.4-3.7)$ & 2.3 & $(1.2-4.2)$ & 1.4 & $(0.8-2.6)$ & $<0.01$ \\
\hline Trachea, bronchus, and lung & 4.6 & $(2.6-8.1)$ & 5.9 & $(3.0-11.3)$ & 1.5 & $(0.7-3.3)$ & $<0.01$ \\
\hline \multicolumn{8}{|l|}{ Other diseases } \\
\hline Ischaemic heart disease & 1.9 & $(0.7-4.9)$ & 1.6 & $(0.9-2.8)$ & 1.8 & $(1.1-2.8)$ & 0.01 \\
\hline $\begin{array}{l}\text { Chronic obstructive pulmonary } \\
\text { disease }\end{array}$ & 2.2 & $(1.2-4.1)$ & 1.8 & $(0.7-4.5)$ & 1.3 & $(0.6-2.8)$ & 0.01 \\
\hline Peptic ulcer & 8.5 & $(1.5-46.6)$ & 4.1 & $(0.3-50.4)$ & 10.9 & $(2.3-52.2)$ & 0.07 \\
\hline
\end{tabular}

${ }^{\star}$ Relative risk was not estimated due to the small number of deaths.

All analyses were adjusted for age and other potential risk factors. See text for details.

analyses of mortality from ischaemic heart disease, other heart diseases, cerebrovascular disease, and hypertension.

Population attributable risk percentage (PAR\%) for cigarette smoking - the proportion of deaths in a population attributable to cigarette smoking - was calculated for a given cause of death using the following formula ${ }^{16}$ :

$\mathrm{AR} \%=\mathrm{P}(\mathrm{RR}-1) /[1+\mathrm{P}(\mathrm{RR}-1)]$

where $P$ is the prevalence of current smokers in the population and RR is the relative risk of dying from the cause of death for current smokers compared with never-smokers as the referent group. The prevalence of current smokers in the Taiwanese population aged 40 years or older was $53.4 \%$ for men and $4.2 \%$ for women. ${ }^{15}$ The number of smoking-attributable deaths for a given cause was derived by multiplying the PAR\% for the cause of death by the total number of deaths from the cause in the population.

All quoted $\mathrm{p}$ (probability) values were based on two-sided tests.

\section{Results}

The frequency distributions of the sociodemographic characteristics of study subjects at recruitment are shown in table 1. Among 14397 subjects recruited, $77 \%$ were men and
$23 \%$ were women. In this cohort, men were older and had a higher educational level than women. There were relatively more women residing in metropolitan areas. A total of 6483 men $(68.8 \%)$ and 130 women $(3.9 \%)$ were ever-smokers. Among them, 1258 men $(19.4 \%)$ and 11 women $(8.5 \%)$ were ex-smokers. The prevalences of current cigarette smokers in men and women of this study cohort were similar to those of the general population in Taiwan $^{15}$ as table 2 shows.

The characteristics of cigarette smoking among current smokers at recruitment are shown in table 3 . The mean duration of smoking was 33 years. The average age of smoking initiation for men and women was 22.4 and 31.5 years, respectively. In general, female smokers had smoked fewer cigarettes per day for a shorter duration than male smokers.

During the period of follow up, 2552 deaths occurred among cohort members. Table 4 shows RRs of dying from various causes of death for current cigarette smokers compared with never-smokers. RRs for some causes of death were not able to be estimated due to the small number of deaths.

In men, cigarette smoking was significantly associated with an increased risk of dying from 
Table 8 Relative risks (RR) and 95\% confidence intervals (CI) of dying from major diseases according to cumulative cigarette smoking among cigarette smokers at recruitment compared with never-smokers as the referent group

\begin{tabular}{|c|c|c|c|c|c|c|c|}
\hline \multirow[b]{3}{*}{ Cause of death } & \multicolumn{6}{|c|}{ Cumulative cigarette smoking (pack-years) } & \multirow[b]{3}{*}{$p$} \\
\hline & \multicolumn{2}{|l|}{$<20$} & \multicolumn{2}{|c|}{$20-40$} & \multicolumn{2}{|l|}{$\geqslant 41$} & \\
\hline & $R R$ & $(95 \% C I)$ & $R R$ & $(95 \% C I)$ & $R R$ & $(95 \% C I)$ & \\
\hline All causes combined & 1.31 & $(1.16-1.47)$ & 1.33 & $(1.18-1.50)$ & 1.27 & $(1.11-1.45)$ & $<0.01$ \\
\hline \multicolumn{8}{|l|}{ Cancer } \\
\hline All sites combined & 1.1 & $(0.9-1.3)$ & 1.7 & $(1.3-2.1)$ & 2.0 & $(1.5-2.6)$ & $<0.01$ \\
\hline Lip, oral cavity, and pharynx & 1.9 & $(0.2-21.2)$ & 3.9 & $(0.4-34.4)$ & 11.6 & $(1.2-109.1)$ & 0.01 \\
\hline Nasopharynx & 3.2 & $(0.7-14.5)$ & 3.9 & $(0.9-16.7)$ & 2.8 & $(0.4-18.9)$ & 0.13 \\
\hline Oesophagus & 0.4 & $(0.1-2.1)$ & 2.1 & $(0.8-5.9)$ & 1.2 & $(0.4-4.1)$ & 0.26 \\
\hline Stomach & 1.3 & $(0.6-2.8)$ & 1.5 & $(0.7-3.1)$ & 2.8 & $(1.4-5.8)$ & $<0.01$ \\
\hline Liver & 1.7 & $(1.0-2.9)$ & 2.1 & $(1.2-3.5)$ & 2.5 & $(1.3-4.6)$ & $<0.01$ \\
\hline Trachea, bronchus, and lung & 2.3 & $(1.2-4.4)$ & 4.5 & $(2.4-8.1)$ & 5.3 & $(2.8-10.0)$ & $<0.01$ \\
\hline \multicolumn{8}{|l|}{ Other diseases } \\
\hline Ischaemic heart disease & 1.9 & $(1.2-2.9)$ & 1.9 & $(1.2-3.0)$ & 1.5 & $(0.9-2.5)$ & 0.03 \\
\hline $\begin{array}{l}\text { Chronic obstructive pulmonary } \\
\text { diseases }\end{array}$ & 1.6 & $(0.8-3.4)$ & 2.0 & $(1.0-4.1)$ & 1.8 & $(0.9-3.8)$ & 0.07 \\
\hline Peptic ulcer & 9.5 & $(1.9-46.3)$ & 9.3 & $(1.5-59.2)$ & 9.4 & $(1.3-68.8)$ & 0.06 \\
\hline
\end{tabular}

All analyses were adjusted for age and other potential risk factors. See text for details.

Table 9 Relative risk (RR), population attributable risk percentage (PAR\%), and smoking-attributable deaths (SAD), by disease category and sex

\begin{tabular}{|c|c|c|c|c|c|c|c|c|}
\hline \multirow[b]{2}{*}{ Disease category } & \multicolumn{4}{|l|}{ Men } & \multicolumn{4}{|c|}{ Women } \\
\hline & $R R$ & $P A R \%$ & $\begin{array}{l}\text { Number of } \\
\text { deathst }\end{array}$ & $S A D$ & $R R$ & $P A R \%$ & $\begin{array}{l}\text { Number of } \\
\text { deathst }\end{array}$ & $S A D$ \\
\hline Cancer & 1.5 & 21.3 & & & 1.7 & 2.9 & & \\
\hline Lip, oral cavity, pharynx & 4.2 & 63.3 & 618 & 391 & $\star$ & & & \\
\hline Nasopharynx & 3.9 & 61.0 & 504 & 308 & 夫 & & & \\
\hline Stomach & 1.9 & 32.7 & 1394 & 456 & $\star$ & & & \\
\hline Liver & 2.2 & 39.3 & 3541 & 1392 & * & & & \\
\hline Trachea, bronchus, and lung & 3.7 & 59.3 & 3144 & 1865 & 3.6 & 9.8 & 1200 & 118 \\
\hline Cervix uteri & $\star$ & & & & 5.3 & 15.3 & 1065 & 163 \\
\hline \multicolumn{9}{|l|}{ Cardiovascular diseases } \\
\hline Ischaemic heart disease & 1.8 & 30.2 & 3245 & 979 & 1.9 & 3.6 & 1875 & 68 \\
\hline Other heart diseases & 1.4 & 17.8 & 3263 & 580 & 1.5 & 2.1 & 2763 & 57 \\
\hline Arterial diseases & 3.0 & 51.9 & 255 & 132 & * & & & \\
\hline \multicolumn{9}{|l|}{ Respiratory diseases } \\
\hline Chronic obstructive pulmonary disease & 1.5 & 21.3 & 1616 & 344 & & & & \\
\hline \multicolumn{9}{|l|}{ Other diseases } \\
\hline Peptic ulcer & 4.5 & 65.4 & 526 & 344 & 17.8 & 41.4 & 255 & 72 \\
\hline All causes combined & 1.3 & 13.9 & 58535 & 8161 & 1.8 & 3.3 & 37410 & 1216 \\
\hline
\end{tabular}

†Total number of deaths aged 40 or more years in Taiwan, 1994.

${ }^{\star} \mathrm{RR}$ was not estimated due to the small number of deaths.

all causes combined $(\mathrm{RR}=1.3)$, all cancer sites combined $(\mathrm{RR}=1.5)$, stomach cancer $(\mathrm{RR}=$ $1.9)$, liver cancer $(R R=2.2)$, lung cancer $(\mathrm{RR}=3.7)$, ischaemic heart disease $(\mathrm{RR}=$ $1.8)$, other heart diseases $(R R=1.4)$, and chronic obstructive pulmonary disease $(\mathrm{RR}=$ 1.9). Increased risks that were not statistically significant were noted for cancer of the head and neck (excluding the nasopharynx) $(\mathrm{RR}=$ 4.2), nasopharyngeal cancer $(R R=3.9)$, arterial diseases $(\mathrm{RR}=3.0)$, and peptic ulcer $(R R=4.5)$. However, cancers of the urinary bladder, pancreas, and oesophagus were not associated with current cigarette smoking.

In women, cigarette smoking was significantly associated with an increased risk of dying from all causes combined $(\mathrm{RR}=1.8)$, lung cancer $(R R=3.6)$, and peptic ulcer $(R R=17.8)$. Increased risks that were not statistically significant were noted for all cancer sites combined $(R R=1.7)$, cancer of cervix uteri $(R R=5.3)$, ischaemic heart disease $(R R=1.9)$, and other heart disease $(R R=$ 1.5).

Tables $5-8$ show the dose-response relationships between mortality from various causes of death and the quantity of smoking, duration of smoking, age of smoking initiation, and cumulative cigarette smoking in pack-years. After adjustment for age and sex and other potential confounders, statistically significant doseresponse relationships were observed between mortality from all causes combined, all cancer sites combined, liver cancer, lung cancer, and ischaemic heart disease and all of these measures of smoking (quantity, duration, age of initiation, and cumulative smoking). There were significant dose-response relationships between oral cancer and smoking quantity, stomach cancer and duration and age of initiation, and chronic obstructive pulmonary disease and age of initiation. We also observed significant dose-response relationships between cancers of the oral cavity and stomach and cumulative cigarette smoking. Those who smoked more than one pack of cigarettes a day (compared with never-smokers) had a 65\% increase in risk of dying from all causes of death, $140 \%$ from all cancer sites combined, $650 \%$ from oral cancer, and $730 \%$ from lung cancer, as shown in table 5 .

Percentages of deaths from various causes attributable to cigarette smoking in the general population (PAR\%) are shown in table 9. In men the PAR\% ranged from $21.4 \%$ for other heart diseases to $65.4 \%$ for peptic ulcer, and in women from $2.1 \%$ for other heart diseases to $41.4 \%$ for peptic ulcer. The total numbers of 
deaths in 1994 from various causes among the male and female populations aged 40 years and older in Taiwan are also shown in table 9. Among 58535 male and 37410 female total deaths, 8161 (13.9\% of total deaths) male and 1216 (3.3\% of total deaths) female deaths were attributable to cigarette smoking. Furthermore, $21.3 \%$ of the male cancer deaths and $2.9 \%$ of the female cancer deaths were attributable to cigarette smoking.

\section{Discussion}

This study was the first prospective study to evaluate the health hazards of cigarette smoking in Taiwan. It is important because the epidemic of cigarette smoking-related diseases is emerging in Asia and relatively few prospective studies have been carried out in this region to assess the magnitude of the problem. Cigarette smoking was found to be associated with an increased risk of dying from several major diseases including various cancers, cardiovascular diseases, and pulmonary diseases, similarly to those reported in white populations. However, the numbers of deaths were too small to derive statistically significant RRs for some diseases that have been well documented to be associated with cigarette smoking. These diseases include oral cancer and peptic ulcer in men; and all cancer sites combined, cancer of the cervix uteri, and ischaemic heart disease in women.

Cigarette smoking not only causes excess mortality, but also increases morbidity and may worsen the quality of life. Passive smoking has also been found to cause lung cancer and ischaemic heart disease. ${ }^{17} 18$ Although the increase in risk associated with passive smoking is smaller than that associated with active smoking, the prevalence of passive smoking is high in Taiwan (roughly equal to the prevalence of smoking among Taiwanese men- $50 \%$ to $60 \%$ ). In this study, death rather than disease related to cigarette smoking was chosen as the outcome variable, and health hazards related to passive smoking were not assessed at all. The overall impact of cigarette smoking on the health of people in Taiwan may thus be underestimated in this study. In other words, the RRs, PAR percentages, and smokingattributable deaths from various causes were estimated in a conservative manner.

Lung cancer mortality increased eightfold during the past 30 years for men and women in Taiwan, which is compatible with the increase in per capita consumption of cigarettes since the second world war. But the prevalence of cigarette smoking remains low in Taiwanese women. Passive smoking is one possible cause of the increase in lung cancer mortality in women. The mortality attributable to passive smoking may be substantial, but was not evaluated in our study.

In comparison with previous prospective studies, ${ }^{2-4} 12$ the risks of dying from various diseases associated with cigarette smoking seemed to be lower in Taiwan than in Western countries. In white populations, cigarette smoking was associated with more than $50 \%$ excess risk of dying from all causes combined and approximately $100 \%$ excess risk of cancer mortality. In this cohort study, cigarette smoking among men was associated with only $30 \%$ excess risk of dying from all causes combined and $50 \%$ excess risk in cancer mortality. The corresponding figures for women were $80 \%$ and $70 \%$, respectively.

The smoking-associated excess in risk of mortality from all causes combined was $40 \%$ for men in Shanghai, China ${ }^{14}$ and $20 \%$ for men and women in Japan. ${ }^{12}$ In a recent study on cigarette smoking-related mortality in China, the excess in risk of mortality from all causes combined among rural men was only $40 \% .{ }^{19}$ Thus, the risk of dying related to cigarette smoking seems to be lower in Asian populations than in whites. This may be explained by the following reasons: (a) the tobacco epidemic in Asia is at its early stage, and its overall impact on health has not yet emerged; (b) Asian cigarette smokers may start smoking at older ages and may smoke a smaller quantity compared with white smokers; (c) other major risk factors for various smoking-related diseases may be more prevalent in Asian countries, and the RRs for cigarette smoking may thus be underestimated; and (d) the length of the follow-up period in some of the Asian studies was shorter than that of some studies in Western countries. We consider these reasons in more detail below with respect to Taiwan, and Asia more generally.

The prevalence of cigarette smoking in Taiwan has reached its plateau since 1965. In this cohort study, the mean duration of smoking was 33 years with a follow-up period of 12 years. Thus it seems unlikely that the tobacco epidemic in Taiwan is in an early stage.

In this study cohort, the mean cigarette consumption was 17 cigarettes per day, and the mean age of smoking initiation was 22 years. In comparison with smokers in the United States, ${ }^{20}$ those in Taiwan smoke fewer cigarettes and start smoking at older ages. Thus the lower risks associated with smoking in Taiwan may be due to the older starting age and lower average tobacco consumption compared with white smokers.

As many risk factors other than active cigarette smoking also play important roles in the determination of cancer, cardiovascular diseases, and pulmonary diseases in Taiwan, it is also possible that the RRs estimated for active cigarette smoking may be underestimated. Passive cigarette smoking is one such risk factor. Those who reported themselves as non-smokers in this study were still exposed to environmental tobacco smoke (ETS). In other words, they should be considered as "less exposed" rather than "unexposed" to tobacco smoke. This is especially the case for women than for men. This misclassification of exposure status leads to an underestimate of the RRs for active smoking, with respect to ETS-related conditions such as lung cancer and ischaemic heart disease. This downward bias in RRs for active smoking may be more important in Asian studies than in Western studies because passive smoking is likely to be more prevalent in Asian countries than in Western countries. 
Another possible explanation for the lower RRs in Taiwan is the duration of the follow-up period. A longer follow-up period would likely increase the relative risk estimates. The follow-up period was 12 years in our study; eight years in the Japanese study, ${ }^{12}$ eight years in the Shanghai study, ${ }^{14} 26$ years in the American veterans study, ${ }^{11} 20$ years in the British doctors study, ${ }^{2}$ and 16 years in the Swedish men study. ${ }^{7}$ Thus the duration of the follow-up period was shorter in the Asian studies.

There was no statistically significant increase in smoking-associated risks of dying from cancers of the oesophagus, urinary organs, and pancreas. These cancers have been found to be associated with cigarette smoking in previous studies. The small number of deaths from these conditions during our follow-up period may be one explanation for this discrepancy. Case-control studies to elucidate the risk factors for bladder cancer in Taiwan have consistently shown no association between smoking and bladder cancer; except for cumulative arsenic exposure in the endemic area of blackfoot disease, ${ }^{21}$ no other risk factors for bladder cancer have been well documented in Taiwan. No studies have been conducted to elucidate risk factors for pancreatic and oesophageal cancer in Taiwan; however, the opposite secular trends of increasing cigarette consumption and decreasing mortality from oesophageal cancer in Taiwan after the early $1960 \mathrm{~s}^{22}$ suggests that smoking may not be a major risk factor for oesophageal cancer in Taiwan.

In our study, cigarette smoking was found to be associated with an increased liver cancer risk after adjustment for chronic hepatitis B virus carrier status and alcohol drinking. This result is consistent with those reported previously in China, ${ }^{14}$ Hong Kong, ${ }^{23}$ and Taiwan. ${ }^{24}$ Cigarette smoking and chronic hepatitis $B$ virus carrier status were also reported to act synergistically in the development of hepatocellular carcinoma. ${ }^{25}$ The $\mathrm{RR}$ estimate derived by adjustment for chronic hepatitis B virus carrier status and the PAR\% of liver cancer deaths for cigarette smoking may thus be underestimated.

The RR of dying from lung cancer was only 3.7 for men in our study. It was similar to that reported from the Japanese cohort study, ${ }^{12}$ lower than that $(\mathrm{RR}=6.5$ for ever-smokers vs never-smokers) observed in the Shanghai study, ${ }^{14}$ and far below those observed in white populations. ${ }^{2-4}$ However, the RR was 8.3 among current smokers who smoked more than one pack per day, which was compatible with that found in the Shanghai study $(R R=9.4)$.

Cigarette smoking has been documented as the most important risk factor for obstructive airways disease. However, only a modest increase in the risk of dying from the disease $(R R=1.9)$ was observed among smokers in this study. The RR was much lower than that ( $R R \approx 10$ for smokers vs non-smokers) found in Western populations, ${ }^{23}$ but similar to that reported in the Shanghai study $(\mathrm{RR}=1.4$ for ever-smokers vs never-smokers). ${ }^{14}$ One possible explanation for this disparity may be the inaccuracy in diagnosis of chronic obstructive airway disease in Taiwan. Many patients with chronic obstructive pulmonary disease in Taiwan are misdiagnosed as having asthma, pneumonia, or tuberculosis. The misclassification of cases may cause an underestimate of the $\mathrm{RR}$ of dying from obstructive airways disease for cigarette smoking. The lower RR may also be due to the later starting age and lower level of cigarette consumption among smokers in Taiwan compared with those in Western countries.

Stroke, after cancer, has been the second leading cause of death in Taiwan since 1982 . Although cigarette smoking has been found to be a risk factor for stroke in Western countries, it was not associated with an increased risk of dying from the disease in our study. Hypertension was a more important predictor for stroke in Taiwan, similarly to the report from Shanghai. ${ }^{14}$

As was shown in reports from Western and Shanghai studies, smoking was an important risk factor for ischaemic heart disease in our study. About $30 \%$ of deaths from ischaemic heart disease in Taiwanese men might be attributable to smoking.

In our study, women seemed to have a higher risk of dying from cigarette smoking-related diseases than men. As shown in table 2, female smokers smoked fewer cigarettes, for a shorter duration, and began smoking later in life than did men. But the RRs of dying from various causes among current smokers were higher in women than in men, especially for non-cancer causes of deaths (shown in table 4). Whether this was due to a smaller number of participants and relatively imprecise estimates among women or due to biological and social differences between the sexes deserves further study.

In summary, there was a striking impact of cigarette smoking on the health of Taiwanese. We estimate that 8161 deaths in men aged 40 and older $(13.9 \%$ of total deaths) were attributable to cigarette smoking in Taiwan in 1994. If all deaths related to cigarette smoking were categorised as a classification code for cause of death, then cigarette smoking would become the second leading cause of death in men in Taiwan, after all cancer sites combined. Tobacco control should be established as the top priority among public health programmes in Taiwan.

This study was supported by grants from the Department of Health, Executive Yuan, Taiwan, China.

1 US Department of Health, Education, and Welfare. Smoking and health. Report of the Advisory Committee to the Surgeon General of the Public Health Service. Washington, DC: Public Health Service, 1964. (PHS Publication No. 1103.)

2 Doll R, Peto R. Mortality in relation to smoking: 20 years' observation on male British doctors. BMF 1976;2:152536.

3 US Department of Health, Education, and Welfare. Smoking and health. A report of the Surgeon General, 1979. Rockville, Maryland: Public Health Service, Office on Smoking and Health, 1979. (DHEW Publication No (PHS) 79-50066.)

4 US Department of Health and Human Services. Reducing the health consequences of smoking: 25 years of progress. A report of the Surgeon General, 1989. Rockville, Maryland: Public Health Service, Centers for Disease Control, Office Publication No (CDC) 89-8411.) 
5 Rogot E, Murray JL. Smoking and causes of death among US veterans: 16 years of observation. Public Health Rep 1980;95:213-22.

6 Hammond EC, Seidmen H. Smoking and cancer in the United States. Prev Med 1980;9:169-73.

7 Carstensen JM, Pershagen G, Eklund G. Mortality in relation to cigarette and pipe smoking: 16 years' observation of 25,000 Swedish men. f Epidemiol Commun Health 1987;41:166-72.

8 Freund KM, Belanger AJ, D'Agostino RB, et al. The health risks of smoking: the Framingham Study: 34 years of follow-up. Ann Epidemiol 1993;3:417-24.

9 Paganini-Hill A, Hsu G. Smoking and mortality among residents of a California retirement community. $A m \mathcal{F} P u b-$ lic Health 1994;84:992-5.

10 Kuller LH, Ockene JK, Meilahn E, et al. Cigarette smoking and mortality. Prev Med 1991;20:638-54.

11 Mclaughlin JK, Hrubec Z, Blot WJ, et al. Smoking and cancer mortality among U.S. veterans: A 26 -year follow-up. Int $\mathcal{f}$ Cancer $1995 ; 60: 190-3$.

12 Hirayama T. A cohort study in Japan. In: Blot WJ, Hirayama T, Hoel DG, eds. Statistical methods in cancer epidemiology. Hiroshima, Japan: Radiation Effect Research Foundation,

13 Suminori A, Hirayama T. Cigarette smoking and cancer mortality risk in Japanese men and women: results from reanalysis of the six-prefecture cohort study data. Environ Health Persp 1990;87:19-26.

14 Yuan JM, Ross RK, Wang XL, et al. Morbidity and mortality in relation to cigarette smoking in Shanghai, China: a prospective male cohort study. $7 A M A$ 1996;275:1646-50.

15 Taiwan Provincial Monopoly Bureau of Tobacco and Wine. Report on marketing survey of tobacco and wine in Taiwan, vols 4-21. Taipei: Taiwan Provincial Monopoly Bureau of Tobacco and Wine, 1964-1992.
16 Riggs JE. Rising lung cancer mortality in the United States, 1968-1988: the manifestation of altered disease competition. Regul Toxicol Pharmacol 1993;18:261-74.

17 Hackshaw AK, Law M, Wald NJ. The accumulated evidence on lung cancer and environmental tobacco smoke. BMF 1997;315:980-8.

18 Law MR, Morris JK, Wald NJ. Environmental tobacco smoke exposure and ischemic heart disease: an evaluation of the evidence. BMF 1997;315:973-80.

19 Niu S, Yang G, Wang G, et al. The Chinese national prospective study of mortality. Proceedings of tenth world conference on tobacco or health, 24-28 August 1997. (In press.)

20 Wynder EL, Taioli E, Fujita Y. Ecologic study of lung cancer risk factors in the U.S. and Japan, with special reference to smoking and diet. $7 p n$ f Cancer Res 1992;83:418-23.

21 Chiou HY, Hsueh YM, Liaw KF, et al. Incidence of internal cancers and inorganic arsenic: a seven-year follow-up study in Taiwan. Cancer Res 1995;55:1296-300.

22 Chen CJ, Chang TL, Liaw YP, et al. Atlas of cancer mortality in Taiwan, 1982-1991. Taipei, Taiwan, China: Department of Health, Executive Yuan, 1996:208

23 Lam KC, Yu MC, Leung JWC, et al. Hepatitis B virus and cigarette smoking: risk factors for hepatocellular carcicigarette smoking: risk factors for hepatocellular

24 Chen CJ, Liang KY, Chang AS. Effects of hepatitis B virus, alcohol drinking, cigarette smoking and familial tendency on hepatocellular carcinoma. Hepatology 1991;13:398406.

25 Chen CJ, Yu MW, Wang CJ. Multiple risk factors of hepatocellular carcinoma: a cohort study of 13,737 male adults in Taiwan. $\mathcal{F}$ Gastroenterol Hepatol 1993;8:S83-7.

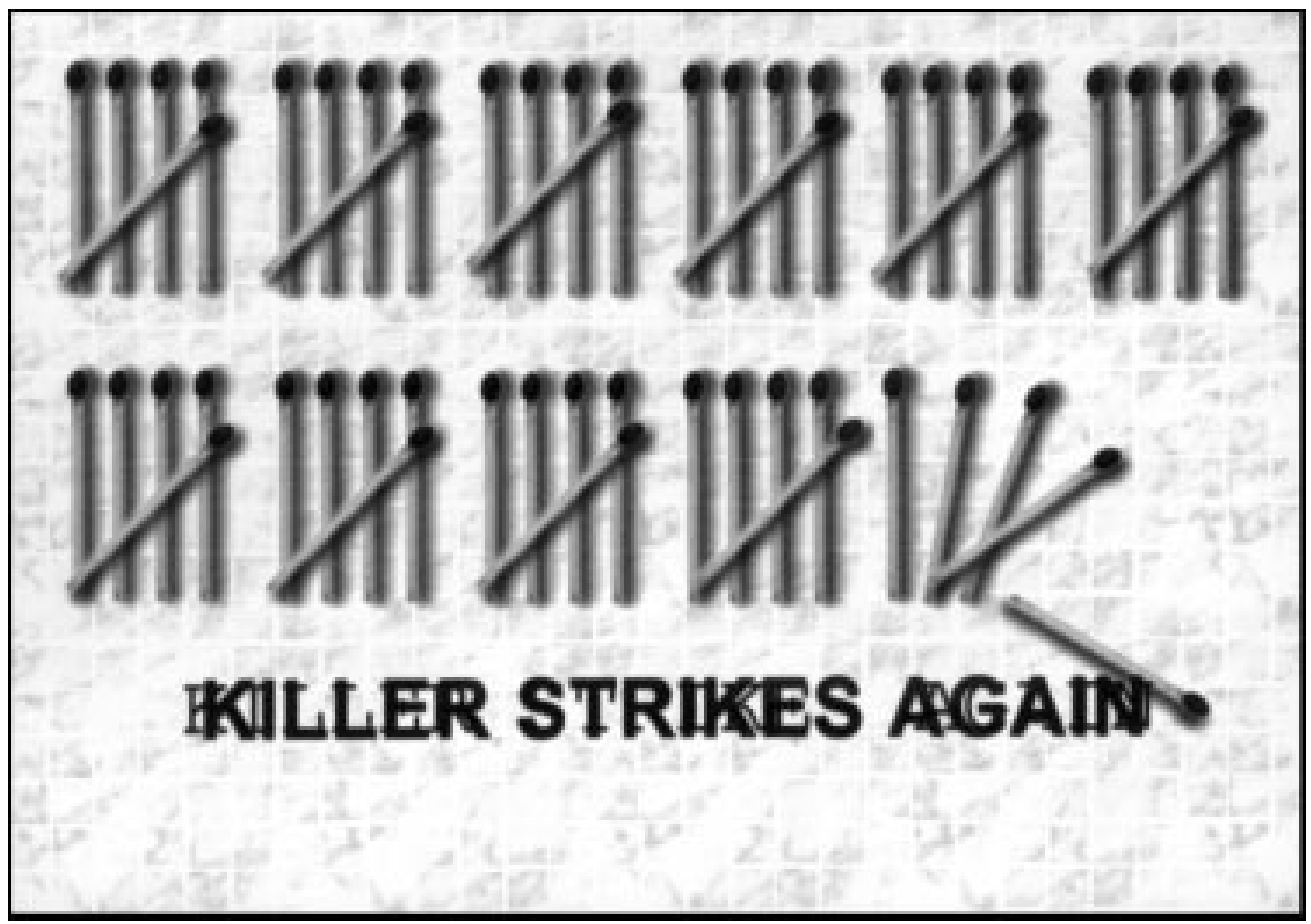

A poster from the National Freephone (toll free) Quitline Service in the United Kingdom as displayed on the Smoke Free Birmingham web site (go to <http://www.smokefree.org.uk/>, then click on "Gallery"). 